\title{
How Student Teachers Use Proportional Number Line to Teach Multiplication and Division of Fraction: Professional Learning in Context of Lesson Study and Open Approach
}

\author{
Tipparat Noparit ${ }^{1,2}$, Jensamut Saengpun ${ }^{2 *}$ \\ ${ }^{1}$ Centre of Excellence in Mathematics, CHE, Bangkok, Thailand \\ ${ }^{2}$ Programme in Mathematics Education, Faculty of Education, Chiang Mai University, Chiang Mai, Thailand \\ Email: tipparat.n@cmu.ac.th, ${ }^{*}$ jensamut.s@cmu.ac.th \\ Received July $7^{\text {th }}$, 2013; revised August $7^{\text {th }}$, 2013; accepted August $14^{\text {th }}, 2013$
}

Copyright (C) 2013 Tipparat Noparit, Jensamut Saengpun. This is an open access article distributed under the Creative Commons Attribution License, which permits unrestricted use, distribution, and reproduction in any medium, provided the original work is properly cited.

\begin{abstract}
The objective of this study is to examine how student teachers use proportional number line in teaching multiplication and division of fractions in context of lesson study and open approach. Teaching experiment was employed to conduct this case study qualitative research with two mathematics student teachers who participated in the study as case studies. This research was carried out in two sixth grade mathematics classrooms from two schools project innovated by lesson study and open approach in the second semester of 2012 academic year. Research data included lesson plans on multiplication and division of fractions, classroom observation with video tape recordings, students' written works and interviewing with the student teachers. The results showed that the student teachers use proportional number line in three ways. Firstly, they use it for asking students to interpret the problems using proportional table aiming at writing equation of the problem correctly in the step of posing open-ended problem situation. Secondly, they use it as a tool for giving student think about how to calculate the answer by themselves. Thirdly, they use it for connecting and checking the various way of thinking about calculation of fractions. The student teachers conceived that learning to teach calculation of fraction with proportional number line is beneficial to their own professional learning in teaching through open approach and student learning and thinking proportionally thought to be the most complex of the elementary mathematics curriculum.
\end{abstract}

Keywords: Proportional Number Line; Multiplication and Division of Fraction; Lesson Study and Open Approach

\section{Introduction}

Abu Ja'far Muhammad ibn Musa al-Khwarizmi, known for short as "al-Khwarizmi" introduced to the Arabic world in Baghdad around $800 \mathrm{BC}$ the Hindu notion of fraction, and showed how operations on these fractions were more or less mechanical, as distinct from the sophisticated relational thought required to interpret and operate with ratios in Euclid's sense (Crossley \& Henry, 1990). What al-Khwarizmi saw was a major intellectual achievement, many students-perhaps mostsee as the first significant cabalistic mystery of mathematics: operations on fractions (Davis, 2003). The mechanical operations on fractions seemed to have the effect of turning teachers' and students' away from the beautiful ideas of proportion and ratio to mechanical manipulation of odd pairs of whole numbers, written as “a/b". Fractions have been said to be the most intricate numbers to deal with in arithmetic and division has been thought to be most complex of mathematical operations. What does happen in school age learning on fraction?

It is hardly surprising that many adolescent students who can apply numerical approaches meaningfully in addition context, not able to apply such approaches to the multiplicative struc-

${ }^{*}$ Corresponding author. tures associated with proportional reasoning (e.g., Karplus, Pulos, \& Stage, 1983). Indeed many of errors that students show in multiplication and division on fraction problems illustrate that they apply additive or subtractive thinking processes rather than multiplicative processes (Karplus et al., 1983). So, exposing students to routine multiplication and division problems of fraction alone has not been effective in helping students to develop deeper understanding of more complex problems needed proportional thinking. This is in part because students need to understand fractions as well as multiplicative concepts (Lo \& Watanabe, 1997). How then to teach operation of fraction for making sense for them?

The teaching and learning of fractions is problematic (Pearn \& Stephens, 2004). Pearn and Stephens (2004) found that this topic was a major problem for students because they did not understand the part-whole relationships described in fraction notation. Teaching this topic should use multiple representations of fractions such as discrete and continuous quantities and the number line. Many students often struggle with how to think about calculating the fraction and interpreting fraction operation problems. In authors' experience, we have much more problems in teaching fraction, especially in teaching the operations on fraction of which the causes can be characterized 
in two parts; the first is teachers' lacking knowledge for teaching fraction with understanding of proportional relationship and the second is lacking linkage between fractions and proportion in mathematics textbooks.

Japanese mathematics textbooks introduced how to think about calculation of fraction with proportional number line in order to develop the way students learn to calculate fraction by/ for themselves (Isoda, 2010). As Kishimoto (2010) defined a proportional number line as use of two number lines to show the multiplicative relationship between two quantities, and can also be referred to as a line segment diagram, a multiple line diagram, a double number line, or a functional scale. The proportional line first came to be widely used in mathematics education when the Japanese educational guidelines announced in 1958 assigned the "concept of ratios" as the implication behind the multiplication and division of decimals and fraction (Kishimoto, 2010). Typical Japanese mathematics textbook (e.g. Gakkoh Tosho, 1995) first used tape diagram represent the quantities at first grade and used tape diagram as a graphic representation of multiplication in fifth grade on unit about decimal multiplication, and the use of proportional number line to calculate multiplication and division problem in sixth grade since 1971. This approach is the consequence of the hundred years of lesson study, Japanese teacher professional development system.

Thailand has adopted lesson study to teacher education by Center for Research in Mathematics Education, Khon Kaen University since 2004. Inprasitha (2010) took open approach as a teaching approach incorporating with lesson study process in order to provide teacher who come to work collaboratively with construct task and problem situation to teach student learning and thinking by/for themselves. In Thailand, lesson study and open approach is then becoming an innovation for Thai teacher professional development that helps teacher recognize this aspect of students' mathematics learning. The Open Approach as "problem solving approach" used in Japan is one shared theory for developing children who learn mathematics by/for themselves (Isoda, 2010). It includes teaching about learning how to learn. The students often gain opportunities to learn mathematics with understanding and meaningful. Inprasitha (2010) has conceived that the "Open Approach" is a teaching approach used in cooperated with lesson study to design learning units and lesson plans. The open approach is consisted of 4 steps as follows: 1) posing open-ended problem situations, 2) students' self-learning, 3) whole-class discussion and comparison, and 4) summarization through connecting students' mathematical ideas emerged in the classroom.

One feature of lesson study in Thailand is usage of Japanese elementary mathematics textbooks (e.g. Gakkoh Tosho, 1995) to design unit and problem situation for teaching in real mathematics classroom. A group of student teacher from faculty of education majoring in mathematics has participated in lesson study and open approach project. They worked with in-service teachers in lesson study process for one academic year and they usually use the Japanese textbook as tool for their planning the lesson. Although they have trained for teaching through open approach, they often struggle with the concept of calculation on fraction with proportional number line embedded in their textbook. With their effort to beyond the struggle, in seminar class for student teacher they took this topic to discuss with their peer and supervisors to think critically on this subject matter and how teaching should be. In this case, the authors concerned that the teachers' learning for teaching mathematics in their professional development is a crucial role to enhance and support students’ learning (Ball et al., 2008; Ma, 1999).

This study aims to provide detailed insight into student teacher's learning by examining how they use proportional number line to teach multiplication and division of fractions. Specifically, we concerned what knowledge student teachers gained from using Japanese mathematics textbooks plentiful with proportional number line and also analyzed the student learning process and outcomes from their teaching through each step of open approach.

\section{Context and Methodology}

This study is a case study qualitative research. The study was employed teaching experiment (Cobb and Steffe, 1983) for conducting the research. Two case studies of mathematics student from program in mathematics education, Chiang Mai University, who taught in sixth grade in Chum Chon Ban Bua Krok Noi school and Ban Mae Sa school, the elementary schools in Chiang Mai province, which participated in the "Project for mathematics teacher professional development innovated by lesson study and open approach in northern educational service areas" since 2009 academic year. The project was conducted by the center for research in mathematics education, Khon Kaen University and the mathematics education program, faculty of education, Chiang Mai University.

The teaching experiment was carried out in two sixth grade mathematics classroom which is each class taught by each student teacher. The first class includes 41 students aged 11 - 12 year and another class with 26 students the same age. Each student teacher taught two chapters on "Multiplication and Division of Fraction" according to the sixth grade Japanese elementary mathematics textbook volume 2 (Gakkoh Tosho, 1995). The first chapter includes "Calculations of Fraction $x$ Whole Number" and "Calculations of Fraction $\div$ Whole Number". Another chapter includes "Calculations of Fraction $\times$ Fraction" and "Calculations of Fraction $\div$ Fraction".

Data were collected during December 2012-January 2013 in the second semester of 2012 school year and included daily videotaped recording of whole unit consecutive lessons on "Multiplication and Division of Fraction" in their mathematics classroom teaching made by two cameras. During each classroom teaching, one camera focused primary on interaction between teacher and student, especially in whole-class discussion. The second camera focused on students' group working. Moreover, documentation consists of lesson plans; students' written works; daily field notes that summarized classroom events and student's ways of thinking. The data from the classroom video recordings of each class were transcribed into protocol and analyzed the way student teachers use proportional number line in teaching calculation of fractions by video analysis. After teaching the unit, the authors interviewed the student teacher after they already taught the unit with the series questions in theme of "What you have learned for teaching calculation of fraction with proportional number line in context of lesson study and open approach?” The interview was recorded, and the transcripts were analyzed according with the video record. 


\section{Results}

\section{Teaching Multiplication and Division of Fractions with Whole Numbers}

Through the analysis of the unit lesson plans on multiplication and division of fraction with whole number, the goal of this learning unit was to explore mathematical ideas, methods and learning processes on multiplication and division of fraction with whole number. Then teachers aimed student to write an expression to represent the given problem situation. Students would be learned how to calculate and solve the problem situations through using unit fraction, commutative law, division rule, drawing, showing the calculation of fraction with tape diagram in order to conclude the concept of multiplication and division of fraction with whole number. The major learning tool of learning unit is "tape diagram" cooperated with "unit fraction" used for think about how to calculate the answer.

In their classroom teaching through open approach on first lesson of the unit, in posing problem session, student teachers posed problem situation according to the textbook as show in Figure 1.

Problem Situation for Calculation of "Fraction $\times$ Whole Number".

"On this fence, $1 \mathrm{dl}$ of green paint is enough for an area of $2 / 5 \mathrm{~m}^{2}$. How many $\mathrm{m}^{2}$ of this fence can be painted by $3 \mathrm{dl}$ of paint?

1) Color in the figure.

2) Write an equation and think about how to calculate the answer.

The teachers attempted to convey their students in class to look for the quantitative relationship between area of painting $\left(\mathrm{m}^{2}\right)$ and quantity of color ( $\left.\mathrm{dl}\right)$ which is represented by fence picture and a number line (Figure 1). The teachers used the illustration to interpret the problem situation and then to write equation for calculation of fraction correctly. Moreover, it lead student to think about how to calculate with using unit fraction as show in Figure 2.

In session of students' self-learning, most students colored the space representing the answer along with the number line. Some of them used repeated addition $\left(\frac{2}{5}+\frac{2}{5}+\frac{2}{5}\right)$ to calculate the problem. Some students concerned the meaning of unit fraction; they looked for one piece of color painting that is representing $2 / 5$ and counted it and multiplied it by 3 . One student in the classroom used proportional number line as the Figure 3 shown. He wrote a sentence near the figure that " 2 multiply 3 is 6". Teacher noticed and took a note this way of thinking.

In whole-class discussion and comparison session, teacher selected and sequenced students' written works for presentation. The ideas for discussing sequenced through repeated addition $\left(\frac{2}{5}+\frac{2}{5}+\frac{2}{5}\right)$ to using proportional number line. Teacher extended the idea of using proportional number from the record to the whole class and asked for discussion (Figure 4).

In summing up the lesson session, teacher attempted to connect the student' ideas from repeated addition, using proportional number line, using unit fraction and multiplication rule respectively. In last session, teacher conveyed student to notice each calculation ideas and then concluded the principle of multiplication of fraction with whole number.

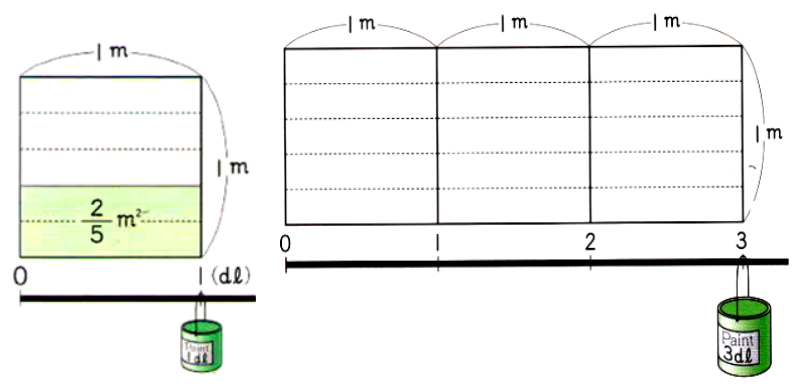

Figure 1.

Representation of problem with picture and a number line (Gakkho Tosho, 2005: p. 3).

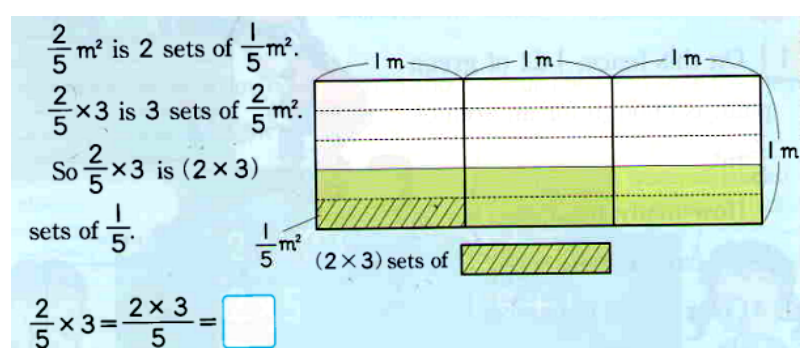

Figure 2.

Calculation with unit fraction (Gakkho Tosho, 1995: p. 4).

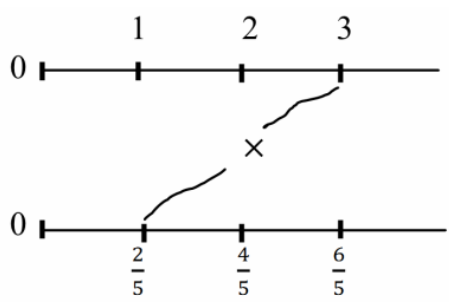

Figure 3.

Student's use of proportional number line.

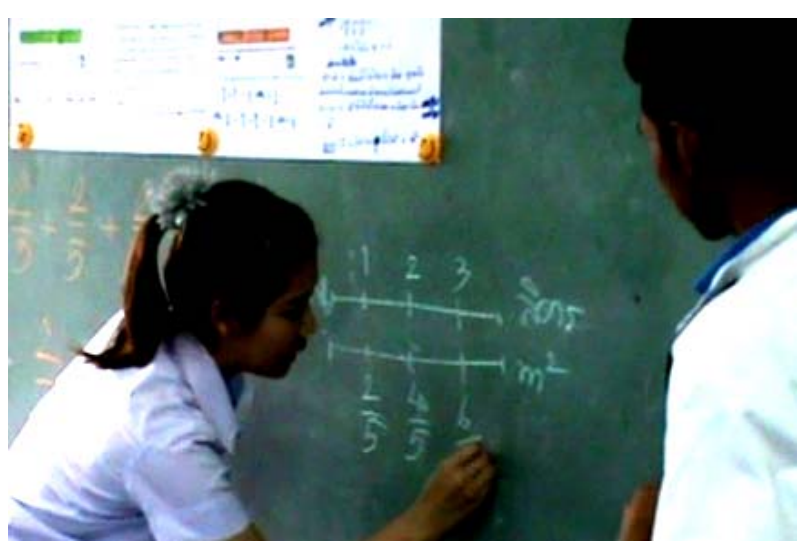

Figure 4.

Teacher's extending proportional number line student used.

From the classroom analysis above, we found that proportional number line emerge from one student. Teacher used the idea of using number line as a tool for extending and connecting with other ideas emerged in the classroom. Moreover, the lesson study team reflected after classroom teaching on the issue about connecting using unit fraction and proportional 
number line during student solving problem. Then, teacher decided to concentrate with designing the lesson plan with proportional number line appropriately in next lesson.

In teaching first lesson on "Fraction $\div$ Whole Number", the student teachers aimed students to write equation Fraction $\div$ Whole Number from analyzing and interpreting problem situation with proportional number line. Although the Japanese mathematics textbook does not approach proportional number line in this topic, but teachers still use it as a tool for thinking about how to calculate the fraction because the students have familiar with and conceived proportional number line to solve the problem. The figure below is the illustration of conception of calculation "Fraction $\div$ Whole Number" that the student teachers generated with themselves and explained it in the les- son plan (see in Figure 5).

Problem Situation for Calculation of "Fraction $\div$ Whole Number".

On this fence, $2 \mathrm{l}$ of paint is enough for an area of $5 / 6 \mathrm{~m}^{2}$.

How many $\mathrm{m}^{2}$ can be painted with each $1 \mathrm{l}$ of paint?

1) Write an equation.

2) How many $\mathrm{m}^{2}$ can be painted with $1 \mathrm{l}$ of paint?

Find the answer by coloring in the figure.

\section{Teaching Multiplication and Division of Fractions with Fractions}

Through the analysis of the unit lesson plans on multiplication and division of fractions with fractions, we found that the goal of this learning unit was to explore mathematical ideas, methods and learning processes on multiplication and division of fractions with fractions. Student will be able to analyze problem situation and then write expression to represent given problem situation easily. Students would be learned how to calculate and solve the problem situations through using crucial learning tools including using unit fraction, proportional table and proportional number line with multiplication and division rule. Student could be used previous concept of multiplication and division of fraction with whole number helping in calculating in this unit. In addition, student could be inferred the principle of multiplication and division of fractions with fractions by themselves.

In their classroom teaching through open approach on first lesson of the unit, the problem situation was posed according to the textbook as show in Figure 6.

Problem Situation for Calculation of "Fraction $\times$ Fraction".

We can cover an area of $4 / 5 \mathrm{~m}^{2}$ with1 $\mathrm{l}$ of blue paint

1) How many $\mathrm{m}^{2}$ can we cover with $1 / 3$ l of paint? Write an equation then check the area by using the figure on the right.

2) How many $\mathrm{m}^{2}$ can we cover with $2 / 3 \mathrm{l}$ of paint? Write an equation.

3) Check the area that can be covered with $2 / 3 \mathrm{l}$ of paint by using the figure on the right.

4) Think about how to calculate the area that can be covered with $2 / 3$ l of paint.

The teacher posed problem 1) first and then asked students to interpret the problem with the figure and coloring the area with $1 / 3$ l of paint. The teacher conveyed students to notice the change in the figure and present the change discussed in form "proportional table". The teacher wrote the table on the blackboard as show in Figure 7.

From Figure 7, in order to write the equation of the problem

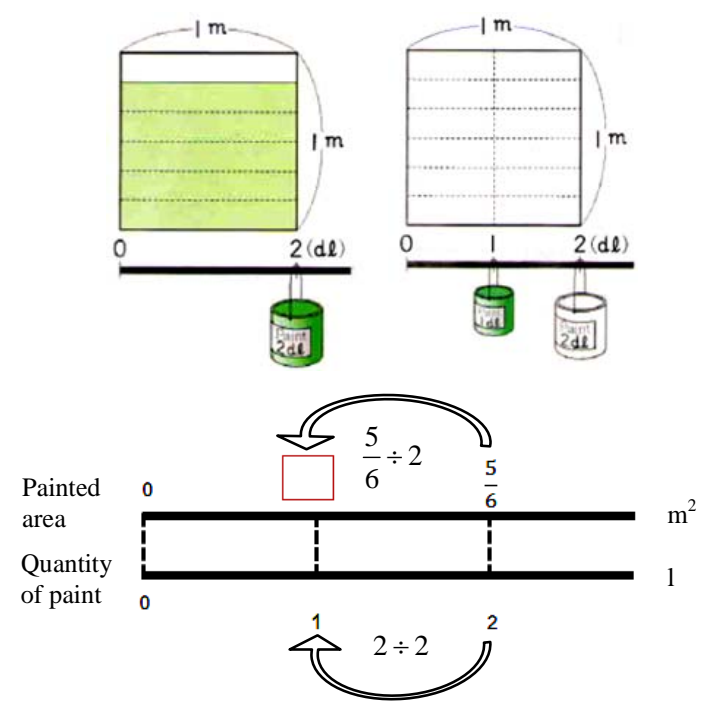

Figure 5.

Proportional number line for Calculation of Fraction $\div$ Whole Number.

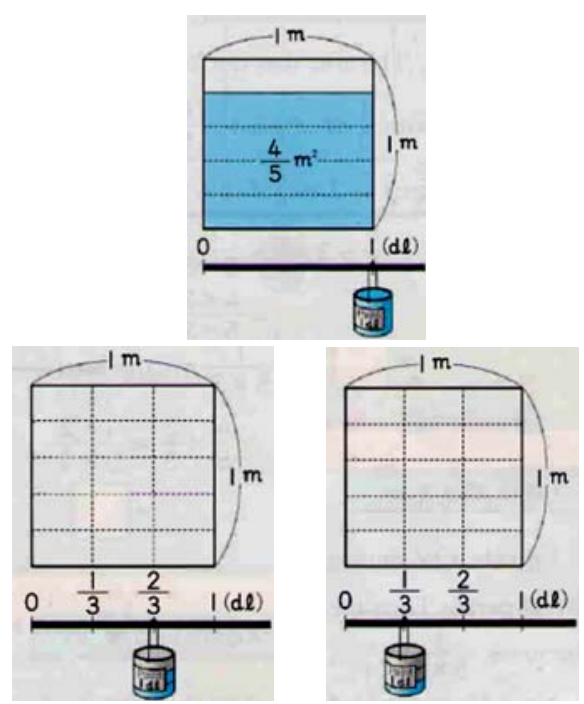

Figure 6.

Problem situation with picture and a number line (Gakkho Tosho, 2005: p. 13).

correctly, the teacher asked student to discuss the proportional table and looked for the area that could be calculated by using multiplication rule. This teaching scene was very important to support student thinking with ratio. Most of student was able to address correctly that the equation for problem 1 ) is $\frac{4}{5} \times \frac{1}{3}$. It leaded student to think about how to calculate the area in problem 1) with proportional number line by themselves.

During students' self-learning in solving problem 2) - 4), students were thinking about how to calculate $\frac{4}{5} \times \frac{2}{3}$ with two ways including:

1) Thinking through proportional number line and using the previous learnt.

2) Thinking through unit fraction. 


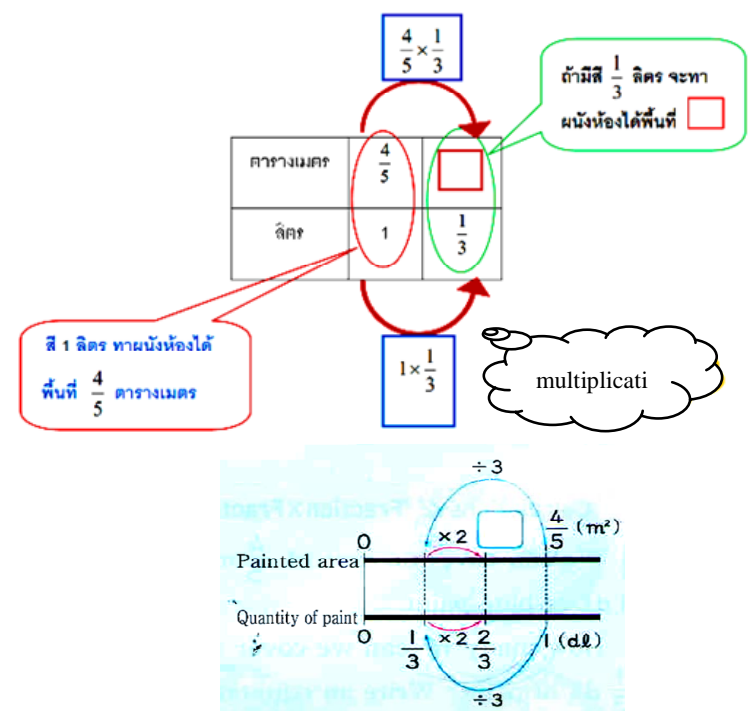

Figure 7.

The use of proportional table.

The students recognized unit fraction of this picture that is $\frac{1}{5 \times 3} \mathrm{~m}^{2}$. They easily addressed that there are $4 \times 2$ set of is $\frac{1}{5 \times 3} \mathrm{~m}^{2}$. Then the area is $\frac{4 \times 2}{5 \times 3}$ or $\frac{9}{15}$.

In whole-class discussion and comparison session, teacher asked students presented their ideas about how to calculate

$\frac{4 \times 2}{5 \times 3}$. The content of discussion and comparison in this lesson both aimed at checking how to use proportional number line and unit fraction and finding the common principle for calculation of Fraction $\times$ Fraction according to students' ideas. In session of lesson summing up, the teacher asked students notice and concluded about common principle for calculation of Fraction $\times$ Fraction that they gained.

From classroom analysis above, proportional table came to be a mediating tool for making the correct equation from the problem situation and it leaded into making the proportional number line in order to think about how to calculate "Fraction $x$ Fraction" objectively and easily. Additionally, another teacher often used proportional number line to check and verify the answer from the other ways of calculation.

The following illustration is some example of learning outcome of students in using proportional number line to calculate and solve problem on "Fraction $\div$ Fraction". It showed the learning process that student able to think proportionally when solving the problem of fraction.

\section{What the Student Teachers Have Learn from Lesson Study and Open Approach Context}

According to analysis of interviewing transcripts, the authors found that both of the teacher student recognized that Japanese mathematics textbook used in the project is very important and has a crucial role in teaching multiplication and division of fraction in mathematics classroom taught by open approach. They accepted that learning calculation of fraction is the most difficulty topic in elementary mathematics especially with interpreting the problems. They told that Japanese mathematics textbooks help teacher and student learn to interpret the problem with using proportional number line. Although in the beginning step of open approach; posing open-ended problem situation, it functions as a tool only for interpretation of problem, but when student comes to solving the problem by them, it takes a role as tool for actual leaning by and for themselves. They conceived that the proportional line helps student write equation represented the problem correctly and easily. Moreover, it help student to think proportionally which is normally hard to understand. They accepted that before they have participated the lesson and open approach project, more and more topic in mathematics they learn by rote learning. When they became to be a student teacher, they recognized that the development of students' learning depend on teacher knowledge about how to teach student to construct leaning tool by themselves. Additionally, working with other teachers in their lesson study team encourages them to develop their knowledge for teaching continually.

\section{Discussion}

This study provided an opportunity to understand how student learn to teach calculation of fraction with using proportional number line in context of lesson study and open approach. As we known, teaching calculation of fraction especially multi-

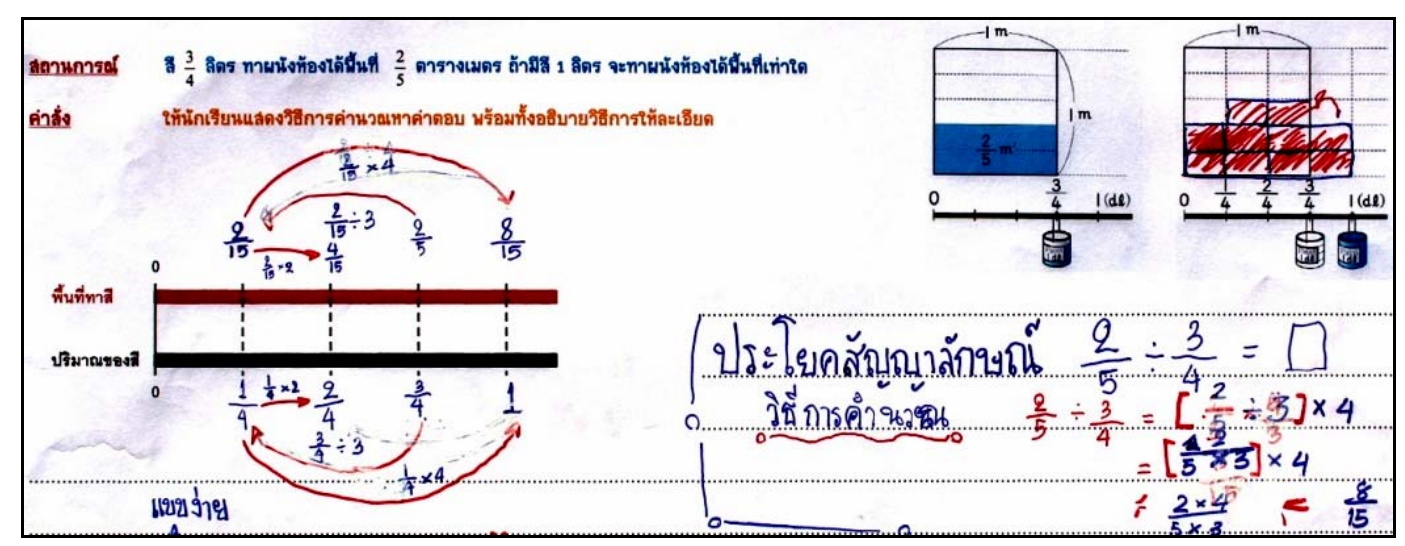

Figure 8.

Example of student's using proportional number line to calculate $\frac{2}{5} \times \frac{3}{4}$. 
plication and division of fraction is very difficult. Teacher often teaches algorithm of calculation of fraction directly without understanding. From the results, we learn important thing in approaches of calculation of fraction in Japanese mathematics textbook used in the project. Fortunately, the student teachers who were participated in lesson study and open approach project were the people who have more curiosity to learn new teaching approach. They use amount of time to read and understand the textbook and discuss together how to design task and how to teach.

The results showed that the student teachers use proportional number line in three ways. Firstly, they use it for asking students interpreting the problems with using proportional table aiming at write equation of the problem correctly in the step of posing open-ended problem situation. Secondly, they use it as a tool for giving student to think about how to calculate the answer by themselves. Thirdly, they use it for connecting and checking the various way of thinking about calculation of fractions.

The results indicated that the student teachers conceived that learning to teach calculation of fraction with proportional number line is beneficial to their own learning and students' learning. For student teachers, it appears that uncovering learning goal with supportive learning tools is very important and needed to know and improve continually (Murray, 1996). For students, they should be provided with opportunities to develop an understanding of fraction concepts with proportional number line before the formal introduction of algorithms. While many students have experienced great difficulty in solving problems that involve fractions (Davis, 1993, 2003; Copp et al., 1983), these students demonstrated proportional thinking and understanding of division of fractions, thought to be the most complex of the elementary mathematics curriculum (Ma, 1999).

The implication of the study here is that when a new generation of student teachers are given the time and the opportunity to explore and develop their mathematical knowledge for teaching in a supportive professional development process such as lesson study and open approach, they become empowered to think about teaching mathematics in order to develop professional learning simultaneously with develop students' learning by /for themselves.

\section{Acknowledgements}

This work was supported by Centre of Excellence in Mathematics, the Commission of Higher Education (CHE), Si Ayutthaya Rd., Bangkok Thailand.

\section{REFERENCES}

Ball, D. L., Thames, M. H. \& Phelps, G. (2008). Content knowledge for teaching: What make it special? Journal of Teacher Education, 59, 389-407. doi:10.1177/0022487108324554

Cobb, P. \& Steffe, L. P. (1983). The constructivist researcher as teacher and model builder. Journal for Research in Mathematics Education, 14, 83-94. doi:10.2307/748576

Crossley, J. N., \& Henry, A. S. (1990). Thus, speak al-Khwarimi: A translation of text of Cambridge University Libery. Historia Math, 17, 103-131. doi:10.1016/0315-0860(90)90048-I

Davis, G. E., Hunting, R. P., \& Pearn, C. (1993). What might a fraction mean to a child and how would a teacher know? The Journal of Mathematical Behavior, 12, 63-76.

Davis, G. E. (2003). Teaching and classroom experiments dealing with fractions and proportional reasoning. Journal of Mathematical Behavior, 22, 107-111. doi:10.1016/S0732-3123(03)00016-6

Gakkoh Tosho (2005). Study with your friends: Mathematics for elementary school $6^{\text {th }}$ grade. Gakkho Taosho, Japan.

Inprasitha, M. (2010). One feature of adaptive lesson study in Thailand-Designing learning unit. In Proceedings of the $45^{\text {th }}$ Korean National Meeting of Mathematics Education, Dongkook University.

Isoda, M. (2010). Japanese theories for lesson study in mathematics education: A case of problem solving approach. In Y. Shimizu, Y. Sekiguchi, \& K. Hatano (Eds.), Proceedings of the 5th East Asia Regional Conference on Mathematics Education, Vol. 1 (pp. 176-181). Tokyo.

Karplus, R., Pulos, S., \& Stage, E. K. (1983). Proportional reasoning of early adolescents. In R. Lesh, \& M. Landau (Eds.), Acquisition of Mathematics concepts and processes (pp. 45-90). New York.

Kishimoto, T. (2010). Proportional number line. In M. Isoda, \& T. Nakamura. (Eds.), Special issue (EARCOME5) mathematics education theories for lesson study: Problem solving approach and the curriculum through extension and integration (pp. 46-47). Tokyo: Bunshoudo Insatusho.

Lo, J. J., \& Watanabe, T. (1997). Developing ratio and proportion schemes: A story of a fifth grader. Journal for Research in Mathematics Education, 28, 216-236. doi:10.2307/749762

Ma, L. (1999). Knowing and teaching elementary mathematics: Teachers, understanding of fundamental mathematics in China and the United States, Erlbaum, Mahwah.

Murray, F. B. (1996). Beyond natural teaching: The case for professional education. In F. B. Murray (Ed.), The teacher educator's handbook: Building a knowledge base for the preparation of teachers (pp. 3-13).

Pearn, C. \& Stephens, M. (2004). Why do you have to probe to discover what Year8 students really think about fraction. In I. Putt, R. Faraghher, \& M. McLean (Eds.), Mathematics education for the third millennium: Towards 2011. Proceedings of the $27^{\text {th }}$ Annual Conference of Mathematics education of the Mathematics Education Research Group of Australasia (pp. 430-437). Townsville, Melbourne. 